\title{
TUTELA SANCIONATÓRIA E TUtELA PREVENTIVA (*)
}

\author{
JOSE CARLOS BARBOSA MOREIRA \\ Professor de Direito Procesual Civil \\ na Faculdade de Direito da UERJ. \\ Desembargador do Tribunal de Justiça \\ do Estado do Rio de Janeiro
}

1. É clássica a idéia de que o processo, como instrumento da realização do direito material, deve proporcionar a quem tenha razão, até onde seja pràticamente possível, "tudo aquilo e precisamente aquilo que ele tem direito de conseguir". Expressou-a, no começo do século, o imenso CHIOVENDA $\left({ }^{1}\right)$, em fórmula tão justa quão elegante, reproduzida a cada passo em artigos e manuais, conferências e tratados. A quem tenha consciência da função social do processo forçosamente se põe como questão de capital relevância a da efetividade da tutela jurisdicional. Desde que o Estado proibiu a justiça de mão própria e chamou a si, com exclusividade, a tarefa de assegurar o império da ordem jurídica, assumiu para com todos e cada um de nós o grave compromisso de tornar realidade a disciplina das relações intersubjetivas prevista nas normas por ele mesmo editadas.

O mecanismo criado para prover a essa necessidade precisa corresponder a uma lógica, mas terrível exigência: atuar de tal maneira que, em toda a extensão da possibilidade prática, venham as coisas a passar-se exatamente como se deveriam passar, de acordo com os preceitos do ordenamento. Que significa isso ao ângulo do jurisdicionado? Recorrendo à Justiça, ele há de poder esperar, ao menos em princípio, que, se o seu direito se vê reconhecido, o processo the proporcione cabal proteção, pondo-o em condições de fruir, de maneira tão completa quanto posível, da vantagem prometida pela norma.

(*) Texto de conferência feita na Faculdade de Direito da Universidade Federal do Paraná (Curitiba), em 22.9.1978, no Ciclo de Palestras de Direito Processual Civil. Acrescentaram-se as notas.

(1) Dell'azione nascente dal contratto preliminare, in Riv. di dir. comm., 1911, e depois nos Saggi do diritło processual e civile, Roma, 1930, vol. I, pág. 110. 
Em outras palavras: o processo avizinha-se do optimum na proporção em que tende a fazer coincidir a situação concreta com a situação abstrata prevista na regra jurídica material; e afasta-se progressiva e perigosamente desse ideal na medida em que o resultado na verdade obtido difere daquele que se obteria caso os preceitos legais fossem observados de modo espontâneo e perfeito pelos membros da comunidade. Semelhante distância entre o direito substantivo e o seu Ersatz é o traço mais dramático da aventura processual; e eliminá-la, ou quando menos encurtá-la, a angústia constante de quantos se preocupam em evitar que a epopéia se resolva ingloriamente numa journée des dupes.

2. Não é preciso grandes esforço para demonstrar que as modalidades de tutela jurisdicional mais prestigiadas pela tradição se revelam, com muita freqüência, incapazes de desempenhar a contento missão de tamanha delicadeza. Sobremaneira insatisfatório mostra-se ao propósito o mecanismo - todavia em geral mimado pelos legisladores e pela doutrina - que se pode representar por meio do esquema "processo de condenação (normalmente de rito ordinário) + execução forçada, máximə quando se reserva, conforme sucede as mais das vezes, para o tratamento exclusivo de situações que se caracterizam pela existência de lesão já consumada( $\left(^{2}\right)$

Dê-se de barato que haja direitos suscetíveis de, lesados, comportar reintegração plena. Ainda com relação a esses, será difícil de atingir a perfeita coincidência entre a realidade e a norma, quando menos pela razão óbvia de que a atividade processual, por mais bem ordenada que seja, nos textos e na prática, sempre consome algum tempo, durante o qual fica o titular privado da utilidade a que fazia jus segundo o direito material. O proprietário pode recuperar a coisa de que outrem se apoderara, o credor pode receber a importância que the era devida, mas nem sequer nessas hipóteses será lícito dizer que $\circ$ processo thes assegurou, efetivamente, vantagem igual à que gozariam se não ocorresse a lesão.

Em todo caso, não convém mininizar o fato de que a certas lesões é realmente mais fácil dar remédio prestadio. Nas dívidas pecuniárias, por exemplo, ainda que tarde um pouco - ou eventualmente muito - o reembolso do credor, dia chega em que a reintegração se opera, e a situação real, se não é a mesma, bastante se aproximará da contemplada na norma, sobretudo quando o próprio direito material, mediante o emprego de técnicas como a da corre-

(2) Vide ao propósito, recentemente, PROTO PISANI, Appunti preliminari sui rapporti tra diritto sostanziale e processo, itt Diritto e G:urisprudenza, vol. 93 (1978), n.० 1, pág. 13 separata. 
ção monetária, toma sobre si o cuidado de prover aos necessários ajustamentos. Resta sempre, é claro, a possibilidade de que a execução se mostre infrutífera; mas seria pouco razoável levar essa emergência à conta do processo, ao qual toca, bem ao contrário, ministrar expedientes idôneos, ao menos em algumas hipóteses e em certa medida, a prevenir o malogro; aí está o arresto, que não tem outra finalidade $\left({ }^{3}\right)$. Seja como for, os direitos de que estamos tratando podem dizer-se, em sentido obviamente diverso do técnico, "privileriados"; e, no que thes concerne, as formas clássicas e habituais de tutela ainda fazem jús a relativa credibilidade - isso sem contar que, em não poucas hipóteses, a lei dispensa tais créditos de submeter-se ao crivo da cognição prévia e desde logo lhes abre a via executiva.

3. O mecanismo começa a "ratear" desairosamente quando se passa das obrigações de dar às obrigações de fazer - sobretudo nos casos de prestação infugível - e às obrigações de não fazer, às quais se pode equiparar, para os fins aqui considerados, as obrigações de tolerar e os deveres de abstenção correspondentes aos direitos chamados "absolutos". Leia-se, no vigente Código de Processo Civil, o art. 642, o primeiro dos dispositivos que integram a secção dedicada à disciplina da execução das obrigações de não fazer: "Se - devedor praticar o ato, a cuja abstenção estava obrigado pela lei ou pelo contrato, o credor requererá ao juz que the assine prazo para desfazê-lo". Logo se vê que, contrariamente à sugestão da rubrica, - de que se trata aí não é da execução de obrigação de não fazer, e sim da execução de uma obrigação secundária, derivada do descumprimento dela, e cuja estrutura é a de uma obrigação de fazer. Que é, com efeito, o desfazer, senão uma simples modalidade do fazer? A obrigação de demolir a obra que se construíra com violação da lei ou do contrato de modo algum consiste in non faciendo, mas in faciendo.

Admitamos que, em certos casos, o resultado final da operação possa proporcionar ao credor, por via oblíqua, utilidade equivalente a de que ele desfrutaria, se não ocorresse a lesão. Restam, porém, os outros - e são numerosos - em que o desfazimento é impossível (quod factum est infectum fieri nequit). Nesses, como prêmio de consolação, acena-se ao cedor com o ressarcimento das perdas e danos, que nem sempre constituirá, ocioso frisá-lo, compensação adequada. E, ainda quando viável, será o próprio desfazimento, afinal de contas, meio sempre hábil para recompor, de forma perfeitamente satisfatória, a malha rompida pela violação? Nem todos os tecidos deixam costurar-se de tal arte que a cicatriz desapareça por inteiro.

(3) Cf. PROTO PISANI, trab. cit., pág. 19. 
Abstraindo-se, no momento, de outras possibilidades, o texto legal tem a melancolia de uma confissão de impotência; nas entrelinhas balbucia-lhe em surdina um pedido de desculpas pela incapacidade da fazer funcionar a contento o instrumental da tutela.

4. A gravidade do problema sobe de ponto quando se pensa nas relações jurídicas de conteúdo não patrimonial, nas situações em que o ordenamento substantivo reconhece ou atribui à pessoa uma vantagem insuscetível de traduzir-se com propriedade em termos pecuniários, ou exclusivamente tais. Basta pensar em certas categorias, longamente negligenciadas em contexto sócio-cultural desfavorável, típico - se quisermos fazer eco à denúncia do filósofo( $\left.{ }^{4}\right)$ - de uma civilização mais voltada para o ter que para o ser, mas que nos últimos tempos vêm atraindo, com intensidade crescæntes, a atenção de juristas inconformados com as lacunas de uma visão puramente economicística do intercâmbio humano.

Recordem-se aqui os direitos da personalidade, cuja elaboração teórica permitiu à nossa cultura, como já se disse com bela fórmula, alcançar "um dos cimos da dimensão jurídica" ${ }^{(5)}$. Desde as espécies clássicas - direito à vida, à integridade física e psíquica, à liberdade, à honra, ao nome, à própria imagem - até os mais modernos desdobramentos, como o direito à preservação da intimidade, cuja carência de proteção se reveste em nosos dias de tons dramáticos, ante o refinamento de certas técnicas, não há quem não perceba o caráter de franca mistificação que assume aí, em regra, uma tutela atuada em termos de simples compensação pecuniária. Certas coisas, sabe-o bem o povo, não há dinheiro que pague.

Dir-se-á que a proteção dos aludidos bens jurídicos, ou de alguns deles, compete precipuamente à Administração, ou em termos mais específicos à polícia. Não creio, porém, que seja uma saída airosa para o processo civil, chamado às falas na matéria, limitar-se a dizer: "Não é comigo" - ou, se preferirem uma expressão técnica, alegar secamente a sua própria falta de legitimatio ad causam...

Análogo discurso poderia fazer-se com referência aos denominados "interessas coletivos" ou "difusos", que hoje em dia constituem tema de fascínio particular sobre grande número de espíritos $\left({ }^{6}\right)$. Con-

(4) GABRIEL MARCEL, Etre et avoir, Paris, 1935.

(5) PONTES DE MIRANDA, Trałado de Direito Privado, t. VII, Rio de Janeiro, 1955, pág. 6.

(6) Vide sobre o assunto, em nosso país BARBOSA MOREIRA, A açäo popular como instrumento de tutela jurisd'cional dos chamades "interesses difuscs", in Temas de Direito Processual, S. Paulo, 1977, págs. 110 e segs.; ADA PELLEGRINI GRINOVER, A tutela iurisdicional dos interesses difusos (tese apresentada a VII Conferência Nacional da Ordem dos Advogados do Brasil), passim (em ambos os trabalhos, extensas referências bibliográficas de direito estrangeiro). 
sidere-se por um instante o caso do interesse na sanidade do ambiente, ou na preservação das belezas naturais e do equilíbrio ecológico, ou na honestidade das mensagens de propaganda; o do interesse em que não se ponham à venda produtos alimentícios ou farmacêuticos nocivos à saúde, em que funcionem com regularidade e eficiência os serviços de utilidade pública, prestada pela Administração ou por particulares, e assim por diante. Se a Justiça civil tem aí um papel a desempenhar, ele será necessariamente o de prover no sentido de prevenir ofensas a tais interesses, ou pelo menos de fazê-las cessar o mais depressa possível e evitar-lhes a repetição; nunca $o$ de simplesmente oferecer aos interessados o pífio consolo de uma indenização que de modo nenhum os compensaria adequadamente do prejuízo acaso sofrido, insuscetível de medir-se com o metro da pecúnia.

5. Atingimos aqui o nó central do problema. Se não é viável, ou não é satisfatória, a modalidade tradicional de tutela consistente na aplicação de sanções, quer sob a forma primária da restituição ao estado anterior, quer sob as formas secundárias da reparação ou do ressarcimento, o de que precisam os interessados é de remédios judiciais a que possam recorrer antes de consumada a lesão, com o fito de impedi-la, ou quando menos de atalhá-la incontinenti, caso já se esteja iniciando. Em vez da tutela sancionatória, a que alguns preferem chamar repressiva $\left({ }^{7}\right)$, e que pressupõe violação ocorrida, uma tutela preventiva, legitimada ante a ameaça de violação, ou mais precisamente à vista de sinais inequívocos da iminência desta.

Por "tutela preventiva" não queremos designar neste passo um gênero de providências judiciais como as que disciplina o nosso vigente Código, no Livro III, sob a rubrica "Das medidas cautelares". Afastando de caso pensado preocupações puramente terminológicas, lembraremos que se impõe distinguir, segundo já tem feito a doutrina $\left({ }^{0}\right)$, entre duas entidades, dois tipos de remédios que às vezes se vêem confundidos. Um deles tende a assegurar de modo imediato a eficácia do próprio processo, e só indiretamente protege o direito substantivo litigioso; assim, não postula a cabal demonstração da existência deste, e por outro lado é utilizável ainda quando decorrente da lesão, um segundo dano, consistente na supressão ou na redução dos meios de que se dispõe para tentar compor o primei-

(7) Assim, v.g., CALAMANDREI, Introducc:ón al estudio sistemático de las providencias cautelares, trad. esp. de Santiago Sentis Melendo, Buenos Aires, 1945, pág. 41; DINI, I provvedimen ti d'urgenza nel diritto processuale civile, 40 ed., Milão, 1973, págs. 18 e segs.; PROTO PISANI, trab. cit., págs. 13, 17.

(8) Vide, entre outros, CALAMANDREI, ob. cit., págs. 40/1, 82/3; a CALVOSA, La tutela cautelare, Turim, s/d (1963), págs. 166/7 (e nota 24); DINI, ob. cit., págs. 22/3; FRIGNANI, L'injuction nella common law e l'inibitoria nel diritto iłaliano, Milão, 1974, págs. 463 e 
ro. $O$ outro tipo visa a proteger de maneira direta a situação material em si, razão por que a providência judicial descansará no prévio acertamento do direito (lato sensu) e jamais assumirá feição de provisoriedade, nem podendo qualificar-se de instrumental senão no sentido genérico em que o é todo o processo, mas apresentando em qualquer caso caráter definitivo - ou, se quisermos usar linguagem tipicamente narneluttiana, "satisfativo". $\left({ }^{9}\right)$

E a esse tipo, e não ao anterior, que estamos aludindo ao falar de "tutela preventiva". Todos percebem a superioridade dela, em confronto com a tutela meramente sancionatória, nas hipóteses há pouco recordadas. E parece igualmente fácil compreender que, para garantir-lhe o máximo de eficiência, se torna necessário revesti-la de formas procedimentais particularmente simples e expeditas, já que - interesse na atuação do mecanismo judicial emerge, em regra, da urgência do remédio, vale dizer, da iminência da ofensa, e bem assim armá-la de efetivo poder de coerção, através de medidas tendentes a influir no ânimo do provável infrator, com força bastante para induzi-lo à abstenção.

6. O receituário do direito brasileiro, nessa matéria, conhece remédios específicos, dignos de crédito pelos bons serviços que muitas vezes têm prestado, quando postos à prova. Mesmo a deixar de lado - habeas corpus preventivo, para não extravar do campo civil, aí estão - mandado de segurança, também preventivamente utilizável em favor de quem tenha "justo receio" de sofrer lesão de "direito líquido e certo", "por parte de autoridade" que se prepare para agir "ilegalmente ou com abuso do poder" (Lei n. ${ }^{\circ} 1.533$, de 31.12.1951, art. $\left.10^{\circ}\right)$; e a ação popular, na medida em que se pode exercitar antes de consumado o dano ao bem "de valor econômico, artístico, estético, histórico ou turístico" (Lei n. ${ }^{\circ} 4.717$, de 29.6.1965, art. 1. ${ }^{\circ}, \S 1 .^{\circ}$, com a redação dada pela Lei $n .^{\circ} 6.513$, de 20.12 .1977 , art. 33), isto é, antes que se converta em fato administrativo o ato administrativo impugnado (10), e sobretudo na medida em que enseja a prevenção da ofensa pela suspensão liminar dos efeitos desse ato (Lei $n .^{\circ} 4.717$, art. $5 .^{\circ}, \S 4 .^{\circ}$, acrescentado pela Lei $n .^{\circ} 6.513$, art. 34).

Esses instrumentos, porém, atuam essencialmente no terreno publicístico. Para os litígios entre particulares, sejam indivíduos ou cole-

(9) CARNELUTTI, Carattere della sentenza di fallimento, in Riv. di dir. proc. c iv., vol. VIII (1931), parte 1I, pág. 171. Interessante registrar que o mestre, tendo dito aí preferível essa designação à outra, nas obras posteriores continuou entretanto a falar de "processo definitivo" por oposição a "processo cautelar": vide, por exemplo, Instifuciones del nuevo proceso civil italiano, trad. esp. de Jaime Guasp, Barcelona, s/d (1942), pág. 62.

(10) HELY LOPES MEIRELLES, Mandado de segurança e ação popular, 4.a ed., S. Paulo, 1976, pág. 68; BARBOSA MOREIRA, trab. cit., pág. 121. 
tividades, não se encontram à disposição dos interessados remédios de tão pronto aviamento e de tão amplo alcance. Basta correr os olhos pelo Livro IV, Título I, do estatuto processual de 1973, para verificar que, dentre os vários "procedimentos especiais de jurisdição contenciosa" aí disciplinados, apenas dois se ordenam à prestação de tutela característicamente preventiva: o interdito proibitório, pelo qual "o possuidor direto ou indireto, que tenha justo receio de ser molestado na posse, poderá impetrar ao juiz que o segure da turbação ou esbulho iminente, mediante mandado proibitório em que se comine ao réu determinada pena pecuniária, caso transgrida o preceito" (Código de Processo Civil, art. 932), e a nunciação de obra nova, que compete: "ao proprietário ou ao possuidor, a fim de impedir que a edificação de obra nova em imóvel vizinho the prejudique o prédio, suas servidões ou fins a que é destinado"; "ao condômino, para impedir que o co-proprietário execute alguma obra com prejuízo ou alteração da coisa comum"; finalmente, "ao Município, a fim de impedir que o particular construa em contravenção da lei, do regulamento ou de postura" (art. 934, n. ${ }^{\circ}$ I, II e III), tudo sob "cominação de pena para o caso de inobservância do preceito" (art. 936, n. II). Mesmo assim, quanto à segunda caberia a ressalva de que, pelo menos à luz da letra de alguns textos, pressupõe obra começada, ou seja, violação não só poìencial, mas já atual.

O mais grave, contudo, não é isso. Abstraindo-se da nunciação para obstar a construção ilegal (art. 934, $\mathrm{n}^{\circ}$. III), a tutela preventiva, mediante procedimento especial, fica ordenada no Código, de maneira exclusiva, à proteção da posse e da propriedade. Mal se justifica o tratamento privilegiado, se se considerar, de um lado, que a eventual lesão, representada pela turbação, pelo esbulho ou pela execução da obra irregular, comporta em geral reparação satisfatória sob a forma da restituição ao estado anterior; de outro lado, que o favor dispensado a tais posições jurídicas mais realça, pelo contraste, o desamparo em que jazem outras, de modo particular exatamente algumas para as quais a falta de adequada tutela preventiva não raro significa, na prática, denegação pura e simples de tutela (direitos não patrimonais, interesses "coletivos" ou "difusos"). Essas têm de submeter-se às delongas do procedimento ordinário, ou na melhor hipótese aos tropeços de um procedimento sumaríssimo, que vai acabando por tornar-se, ao menos em certas comarcas, mais demorado que aquele...

Dir-se-á que as socorre, quando nada em caráter provisório, o poder cautelar genérico em boa hora atribuído expressamente ao juiz pelo vigente Código. Mas a tutela cautelar é, por sua própria índole, instável. Ademais, recai-se numa inútil duplicação de processos, quan- 
do a rigor bastaria um, se bem estruturado, para compor o litígio. E, afinal, porque se há de dar a título de cautela, aquilo que já se poderia dar sob a forma de prestação jurisdicional satisfativa?

7. Cumpre verificar se restam outras possibilidades. A ação declaratória costuma ser apontada em setores doutrinários como instrumento capaz de prevenir violações ( $\left.{ }^{11}\right)$. Exclui-se desde logo a hipótese, à evidência, no caso de ajuizar-se a demanda depois da consumação da ofensa, conforme curiosamente fez questão de permitir, expressis verbis, 0 art. $4 .^{\circ}$, parágrafo único, do diploma em vigor. Antes, é possível que ela desempenhe praticamente a aludida função, desde que a parte vencida saia também convencida e se resolva a cumprir a obrigação em tempo oportuno. Como meio de intimidação, depois de coerção, todavia, o remédio é fraco: basta pensar que, na eventualidade de inadimplemento, o titular do direito lesado terá de voltar a juízo para pleitear a condenação do infrator, ao qual se concede assim uma folga em boa medida tranquilizadora.

Que dizer da condenação para o futuro ${ }^{\left({ }^{12}\right)}$, isto é, da condenação anterior à lesão? Sua possibilidade em certos casos é inequívoca no sistema do Código: assim, quanto às relações jurídicas sujeitas a condição ou termo, ela resulta inquestionavelmente do disposto no art. 172; e no tocante às obrigações de não fazer, o art. 287 parece ministrar-lhe base sólida. Há quem acrescente a hipótese das prestações periódicas vincendas, com invocação do art. $290\left({ }^{13}\right)$. De qualquer maneira, é pena que o legislador de 1973, tão preocupado com a admissibilidade da mera declaração posteriormente à ofensa, não tenha dedicado pelo menos igual atenção ao caso oposto, no entanto de muito maior interesse prático: mais fácil encontrar quem deseje obter a condenação prévia do devedor que dá sinais claros de pouca disposição para adimplir - manifesta como é, para o credor, a vantagem de munir-se antecipadamente do título, pondo-se em condições de utilizar a via executiva tão logo se concretize o inadimplemento do que descobrir quem se interesse pela satisfação "platônica" de ver simplesmente declarada, sem conseqüências outras, a existência de direito já violado, ao qual nenhum socorro eficaz normalmente prestará o puro acertameto judicial. Tinha o Código à vista o exemplo da secular Ordenação alemã, cujo § 259 admite, em termos genéricos, - pedido de condenação para o futuro, desde que justificado pelas circunstâncias o receio de que o devedor se furte ao cumprimento

(11) Sobretudo na literatura francesa: vide, por todos, GIGNOUX, Les actions préventives, Paris, 1935, págs. 85 e segs.

(12) Vide, sobre o assunto, a monografia clássica de ROGNONI, La condanna in futuro, Milão, 1958.

(13) CALMON DE PASSOS, Comentários ao Código de Processo Civil, vol. III, 2.a ed., Rio de Janeiro, 1977, págs. 257 e segs. 
tempestivo da obrigação; nesse modelo talvez se pudesse haver coIhido alguma sugestão valiosa.

8. Mas nem sequer era indispensável que nos abeberássemos em fontes estrangeiras. No particular, a nossa própria tradição jurídica em verdade constituía manancial suficiente. Essa tradição, que vem de longe, produzira no Código de 1939 fruto precioso: uma figura genérica de tutela preventiva das obrigações de fazer e não fazer, nas vestes da ação cominatória do art. 302, n. ${ }^{\circ}$ XII, concedida, "em geral, a quem, por lei ou convenção, tiver direito de exigir de outrem que se abstenha de ato ou preste fato dentro de certo prazo". O traço característico da ação cominatória consistia, como se sabe, no fato de que a comunicação da demanda ao réu assumia caráter de preceito ou comando: após cognição inicial sumária e provisória, ordenava o juiz ao devedor que se abstivesse do ato proibido, ou que praticasse o ato devido, sob a ameaça de pena (lato sensu) para o caso de descumprimento. Note-se bem: descumprimento da obrigação, não da sentença final, que viesse a confirmar o preceito. Algo de análogo, em campo diverso, ao que ainda hoje se dá no interdito proibitório e a aproximação parecerá naturalíssima a quem se recordar das velhas Ordenações do Reino, e particularmente do texto do Livro III, Título $78, \S 5 .^{\circ}$, onde o legislador filipino dizia "que a parte, que se teme, ou receia ser agravada per a outra parte, pode recorrer aos Juízes da terra, implorando seu Ofício, que o provejam, como the não seja feito agravo"; e acrescentava, exemplificando: "se algum se temer de outro, que o queira ofender na pessoa, ou the queira sem razão ocupar e tomar suas cousas, poderá requerer ao Juiz que segure a ele e as suas cousas do outro, que o quiser ofender, a qual segurança The o Juiz dará".

A ação cominatória foi vítima de certa jurisprudência mal avisada que, contra os votos da melhor doutrina $\left({ }^{14}\right)$, interpretou o Código de 1939 como se a multa cominada ao devedor pelo inadimplemento só começasse a incidir após o trânsito em julgado da sentença final, ou - variavam as fórmulas liberalizantes - após a nova citação de réu vencido. Assim se concedia a este uma segunda oportunidade, degradando-se em tutela condenatória comum, sancionatória portanto, a tutela preventiva idealizada pelo legislador. Cabe lamentar que o vigente Código, em vez de reagir contra a deturpação, restaurando em sua dignidade a ação cominatória, se haja dobrado a essa funesta orientação, tornando certo, no art. 287, que a "pena pecuniária" só será devida no caso de "descumprimento da sentença".

(14) Representada principalmente por MACHADO GUIMARÃES, Comentários ao Código de Processo Civil, vol. IV, Rio de Janeiro, 1942, págs. 227/9, 232; id., comentário a Acórdão, in Rev. de Dir. Proc. Civ., vol. 2 (1960), págs. 171, 175/6. 
9. A partir dessa constatação melancólica, abre-se campo a uma imprescindível reflexão de lege ferenda, para a qual é oportuno convocar os estudiosos. A propósito de outro assunto, disse alguém certa vez: "Torniamo all'antico, sarà un progresso". Fomos capazes de inventar o mandado de segurança preventivo contra atos de autoridade. Precisamos de um remédio equivalente contra atos ou omissões de particulares. O paralelo nada tem de arbitrário: justamente de "segurança" falava o legislador filipino. E, nos termos da vetusta Ordenação, era possível ao ameaçado pedir ao juiz que o segurasse "a ele e as suas cousas": a pessoa antes dos bens, em sequiência filosoficamente irrepreensível. Na sistemática atual, passa à frente a segurança dos bens, consoante motram os textos relativos ao interdito proibitório e à denunciação de obra nova. Ao que se pode reparar com maior facilidade, dispensa-se a tutela preventiva; ao que não comporta reparação adequada. reserva-se a tutela sancionatória. Paradoxo apenas aparente: se no mais é nítido o primado do ter sobre o ser, como estranhar que o seja também na ordem processual?

Em toda obra legislativa está implícita uma visão do mundo, uma escala de valores. A preferência dada em geral pelos códigos à tutela sancionatória, em detrimento da preventiva, constitui dado valioso para quem se disponha a pesquisar os pressupostos ideológicos do nosso processo. É tarefa que aguarda a atenção das inteligências. Nenhuma competência tenho senão para deixar aqui formulada a sugestão. 